\title{
Transport properties of soil particles in Sakiyamawan-Amitoriwan nature conservation area, Iriomote Island, Japan
}

\author{
Shinya Shimokawa ${ }^{1 *}\left(\mathbb{D}\right.$, Tomokazu Murakami $^{1}$, Hiroyoshi Kohno ${ }^{2}$ and Akira Mizutani ${ }^{2}$
}

\begin{abstract}
The actual states of soil particle transport in and exchange between the Sakiyama and Amitori bays, Iriomote Island, Japan, were investigated using atmosphere-ocean-river observations and numerical simulations. The results show that in summer in both bays large particles $(\geq 15 \mu \mathrm{m})$ do not move from the vicinity of the river mouths. Small particles, however, do move to the respective east sides of the bays. In winter in both the bays, large particles move towards the center of the bays from the vicinity of the river mouths, whereas small particles move to the respective west sides of the bays. Furthermore, soil particles move mainly from the Sakiyama to the Amitori bay in summer, but this direction is reversed in winter. These features are explainable mainly by seasonal differences in wind speed and direction, but the combination among seasonal differences in wind speed and direction, the wind-driven current and the topography is also important for them. The results are useful for assessing soil particle impact on coastal marine ecosystems, such as those containing reef-building coral and Enhalus acoroides, and their effective conservation in the natural conservation areas of the Sakiyama and Amitori bays.
\end{abstract}

Keywords: Iriomote Island, Sakiyamawan-Amitoriwan nature conservation area, Sakiyama bay, Amitori bay, Soil particle, Coastal marine ecosystem, Environmental impact of assessment

\section{Background}

The Sakiyamawan-Amitoriwan nature conservation area, Iriomote Island, is the only oceanic nature conservation area in Japan. The Sakiyama bay was designated as a nature conservation area in 1983. In 2015, the area was extended to include the adjacent Amitori bay (Ministry of the Environment, Government of Japan 2015b; Fig. 1). The area has no access roads, and the bay perimeter is uninhabited; therefore, it is a natural environment with very little human impact. In addition, it has various environmental gradients, such as fresh water and soil inputs from rivers at the innermost parts of the bays, the existence of mangrove forests besides the rivers, and the difference of water depth, length, and reef slope zone between the bays (Kawana 1990; Ukai et al. 2012).

\footnotetext{
*Correspondence: simokawa@bosai.go.jp

${ }^{1}$ Storm, Flood and Landslide Research Division, National Research Institute for Earth Science and Disaster Resilience, 3-1 Tennodai, Tsukuba, Ibaraki 305-0006, Japan

Full list of author information is available at the end of the article
}

The environmental gradients will affect the distribution of coastal marine systems such as those containing reefbuilding corals and Enhalus acoroides (see Appendix 2). For examples, soil particles provide nutrients to them, but disturb respiration of corals and photosynthesis of zooxanthellae. Thus, the conservation and the assessment of environmental impact are urgently and critically needed.

Previous studies have shown that the distributions of reef-building corals (Murakami et al. 2012; Shimokawa et al. 2014b, 2015, 2016; Ukai et al. 2015) and $E$. acoroides (Murakami et al. 2014, 2015a, b; Nakase et al. 2015, 2016) are largely influenced by the environmental gradients and vary with location in the Sakiyama and Amitori bays. However, the impact of soil input from rivers on the coastal marine ecosystems has not been investigated thoroughly in the area, especially in Sakiyama bay.

The purpose of this study is to provide transport properties of soil particles in the region as basic information for the analysis. Due to the remoteness of the study area 


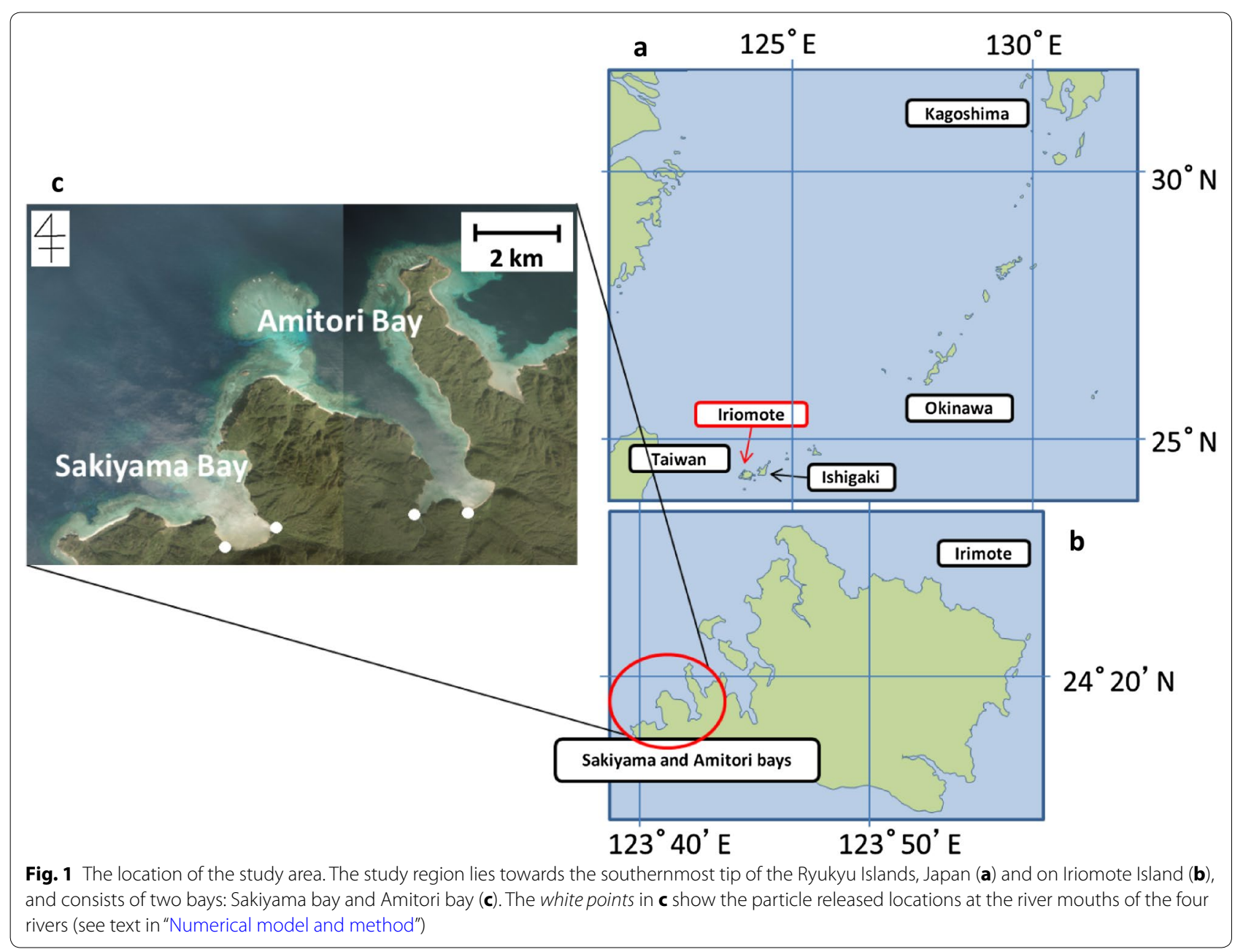

and limited access, broad and continuous observations are difficult to obtain. Therefore, in addition to the observations conducted on site, we used numerical modeling that integrated the observational data into the models. Using the results, we were able to understand the transport properties of soil particles in the study area and the exchange properties between the Sakiyama and Amitori bays in summer and winter seasons.

\section{Numerical model and method}

As an overview, in this study, according to Murakami et al. (2013), the Coastal ocean Current Model (CCM) can be used to reproduce ocean currents in periods with typical summer and winter atmospheric conditions in the area, and subsequently particle tracing analysis can be performed using the Lagrangian method that is applied to soil particles released from the river mouths of the four rivers (Painta, Ubo, Ayanda, and Udara rivers) that enter the Sakiyama and Amitori bays (see Fig. 1). Next, we describe the details of "Numerical model and method."
The CCM is characterized by a multi-sigma coordinate system (Murakami et al. 2011; Shimokawa et al. 2014a), although it is essentially a primitive ocean model. The primitive ocean model is consisted of the Navier-Stokes equations for a fluid element on the surface of our rotating planet with hydrostatic balance, incompressible continuity equation, temperature equation, and salinity equation. The multi-sigma coordinate system can reduce the numerical errors of horizontal pressure gradients and diffusion terms generated in a region with a large bathymetric gradient. Therefore, the CCM is suitable for calculating ocean currents in regions such as the Sakiyama and Amitori bays, which have a large bathymetric gradient ranging from a few meters depth for the coral reefs to 70-m depth for the ocean bottom floor. In fact, previous studies showed that the CCM can reproduce the observations with high precision in Amitori bay (Shimokawa et al. 2014b; see Appendix 2) and also other areas (Murakami et al. 2015c). In addition, the CCM can support accurate calculation of the inflow rates of freshwater 
from rivers because the dependency of the vertical grid spacing on depth is low. Therefore, the CCM is also suitable for particle tracing analysis of soil particles released from the river mouths.

There are two methods for soil-transport analysis: (1) uses an advection-diffusion equation in which soil is treated as a concentration of suspended matter, and (2) uses Lagrangian tracing under flow fields in which soil is treated as a particle with a diameter. The former method can obtain quantitative soil distribution, but the flux of concentration of suspended matter at the boundary to the advection-diffusion equation is needed to be input from observational data. However, there are no observational data from the Sakiyama and Amitori bays at present owing to the logistical difficulties for observation in the area. Therefore, we used the latter method, the Lagrangian particle tracing analysis (e.g., Yanagi 2001; Murakami et al. 2013). This method can calculate soil distribution patterns with a precision of current velocities calculated by an ocean model used in the study (the CCM for our study).

First, we conducted observations of wind speed, wind direction, and precipitation at point A (continuous meteorological observation station), and flow rates at the four rivers by Acoustic Doppler Current Profiler (Fig. 2). Tables 1 and 2 show average meteorological field data observed at point $\mathrm{A}$ in the summer and winter seasons and average flow rates observed at the four rivers in the summer and winter seasons, respectively. For flow rates of the Painta and Ubo rivers in the Sakiyama bay, we used the same values for both the summer and winter seasons because winter observations could not be conducted.

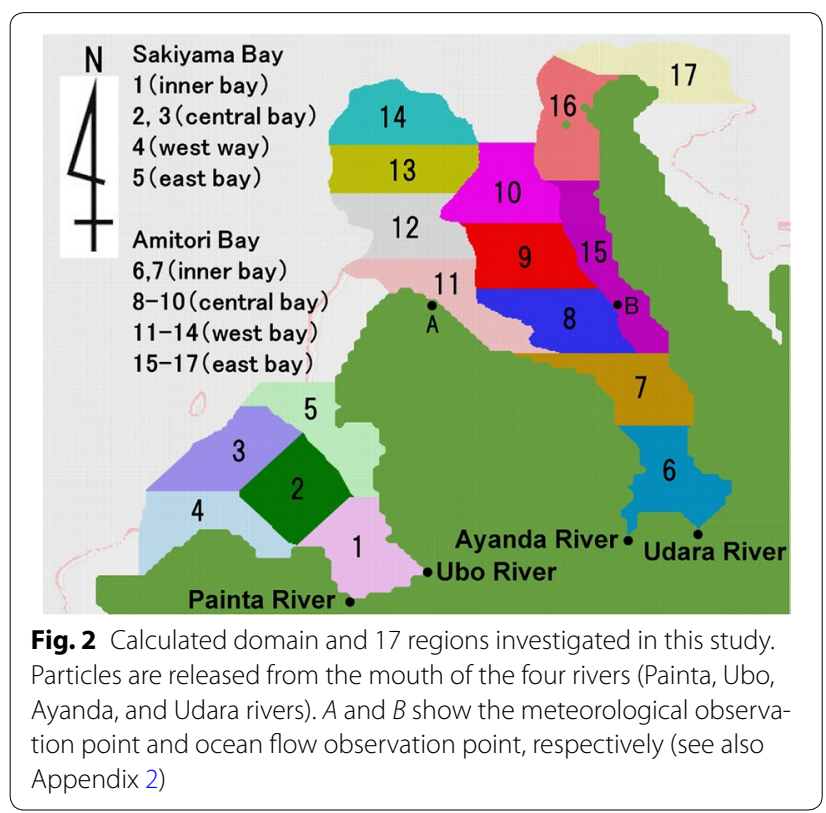

Table 1 Average meteorological field observations at point $A$ (Fig. 2) in the summer and winter seasons

\begin{tabular}{lll}
\hline & Summer & Winter \\
\hline Average wind speed $(\mathrm{m} / \mathrm{s})$ & 3.1 & 5.8 \\
Maximum wind speed $(\mathrm{m} / \mathrm{s})$ & 8.6 & 13.5 \\
Average wind direction & SSE $\left(160^{\circ}\right)$ & ENE $\left(73^{\circ}\right)$ \\
Average precipitation $(\mathrm{mm} /$ day $)$ & 1.5 & 2.9 \\
Maximum precipitation $(\mathrm{mm} /$ day $)$ & 15.5 & 42.5 \\
\hline
\end{tabular}

Table 2 Average flow rates observed at the four rivers (Fig. 2) during summer and winter

\begin{tabular}{lll}
\hline & Summer & Winter \\
\hline Ayanda river $\left(\mathrm{m}^{3} / \mathrm{s}\right)$ & 0.012 & 0.041 \\
Udara river $\left(\mathrm{m}^{3} / \mathrm{s}\right)$ & 0.010 & 0.023 \\
Painta river $\left(\mathrm{m}^{3} / \mathrm{s}\right)$ & 0.011 & Same as that in summer \\
Ubo river $\left(\mathrm{m}^{3} / \mathrm{s}\right)$ & 0.097 & Same as that in summer \\
\hline
\end{tabular}

Next, we reproduced current velocity fields in the Amitori and Sakiyama bays by using the CCM with our field observations, the astronomical tide calculated by a tide model (Matsumoto et al. 2000) as the boundary values and the water temperature and salinity observed by the conductivity-temperature-depth profiler (Murakami et al. 2012) as the initial values. The calculated domain is shown in Fig. 2. The time periods of the calculations were from June 9 to June 29, 2014, and from November 1 to November 22, 2014, which are periods with typical summer and winter atmospheric conditions in this area, respectively. The space resolution is $50 \mathrm{~m}$ in horizontal and 42 layers in vertical. The time step is $1 \mathrm{~s}$.

Then, by using the calculated current velocity fields, Lagrangian particle tracing analysis was performed by assuming the following three conditions: (1) sedimentation by its own weight was calculated by using Rubey's experimental equation (Rubey 1933), (2) there were no diffusion effects, and (3) soil particles that reached the sea floor were not fixed there but could flow only when the Shields number exceeded a critical value. The Shields number is an index of mobility of soil particles on sea or river floors and is defined as $\tau / \rho R g D$, where $\tau$ is the bottom shearing force $\left(\mathrm{N} / \mathrm{m}^{2}\right) ; \rho$ is the density of water $(\mathrm{kg} /$ $\left.\mathrm{m}^{3}\right) ; R$ is the specific gravity in water (dimensionless); $g$ is the gravitational acceleration $(=9.8 \mathrm{~N} / \mathrm{kg})$, and $D$ is the diameter of soil particles $(\mathrm{m})$. There are no observational data on the critical Shields number and the spatial distribution in this region. Therefore, the critical Shields number is set to a constant value $(=0.05)$, which is used in inner bay for previous study (Kawasaki et al. 2008). The mass percentage passing of soil particles from the Ayanda 
and Udara rivers obtained by sediment trap observation at the mouths of the rivers (Shimokawa et al. 2014b) showed that the diameters of the soil particles were distributed mainly from 0.1 to $50 \mu \mathrm{m}$. This study focuses on the distributions of soil particles. To investigate the distributions of soil particles, the size difference of soil particles needs to be included because fine particles reach far places, but coarse particles do not. Therefore, soil particles with diameters of $0.1,1,3,5,8,10,15,20$, and $30 \mu \mathrm{m}$ were released every $10 \mathrm{~s}$ from the river mouths of the four rivers (six grid points for each river; i.e., a total of 24 particles were released every $10 \mathrm{~s}$ for each diameter value, see also Fig. 1c). We assumed here that total sediment loads are same among the four rivers in the numerical experiments because we do not have exact data although the actual loads and the watershed sizes may be different exactly. The initial state is with no particle. Then, the states of the soil particles were classified into bottomed (on the sea floor), floated (in the sea), and landed (from the sea) and time series of soil particle positions were obtained.

\section{Results and discussions}

Figure 3 shows a snapshot of the soil particle distributions with a diameter of $3 \mu \mathrm{m}$ calculated via Lagrangian particle tracing analysis in the final states for the summer and winter seasons (0:00 UTC, June 30 and 0:00 UTC, November 23 in 2014, respectively). Particles with yellow, red, violet, and pink indicate the source from the four rivers (Painta, Ubo, Ayanda, and Udara rivers, respectively).
The results show that for both bays, soil particles tend to accumulate on the east side in summer and the west side in winter and move from Sakiyama bay to Amitori bay in summer and from Amitori bay to Sakiyama bay in winter.

To investigate the characteristics of soil particle distributions, including the difference of distribution by the diameters and moving state (bottomed or floated) of soil particles, Sakiyama and Amitori bays were divided into 17 regions (five regions for Sakiyama bay and 12 regions for Amitori bay; see Fig. 2). The divisions reflected the distributions of reef-building coral (Murakami et al. 2012; Shimokawa et al. 2016) and E. acoroides (Murakami et al. 2014; Nakase et al. 2015), and each region has almost the same areal extent. For example, the west (11-14) and the east regions (15-17) of the Amitori bay correspond to the top of the reef slope (see also Fig. 1), and the inner region of the Sakiyama bay $(1,2)$ corresponds to the habitat of $E$. acoroides (see Appendix 1).

Figure 4 shows the number of soil particles by region, particle diameter, and particle states (bottomed or floated) integrated in summer and winter seasons. In summer, large particles, defined here as particles with a diameter of $>15 \mu \mathrm{m}$, hardly moved from the river mouths for both bays. In particular, floated large particles existed only in the innermost region of the bays. For the Sakiyama bay, total number of soil particles was high in the east side, although the number of bottomed particles was high in the west side and that of floated particles was high in the east side. For the Amitori bay, the total number of soil particles was high in the central bay, but the number

\section{a Summer}

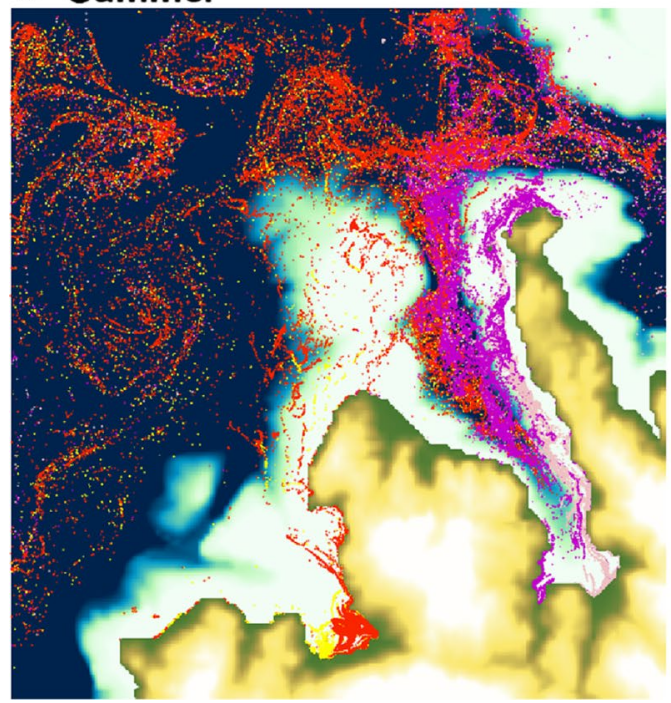

\section{b Winter}

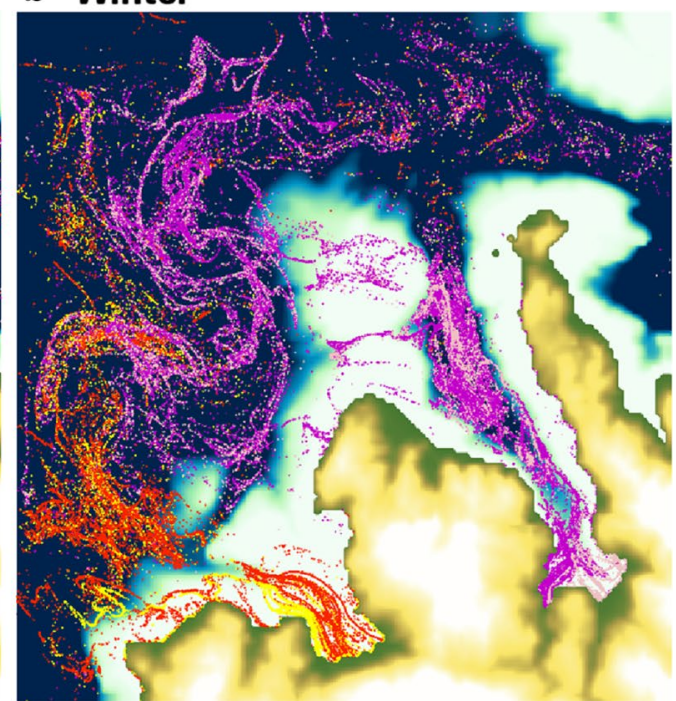

Fig. 3 Distributions of soil particle with a diameter of $3 \mu \mathrm{m}$ in final states during a summer and b winter (0:00 UTC, June 30 and 0:00 UTC, November 23 in 2014, respectively). Yellow, red, violet, and pink dots represent soil particles from the four rivers (Painta, Ubo, Ayanda, and Udara rivers, respectively) 


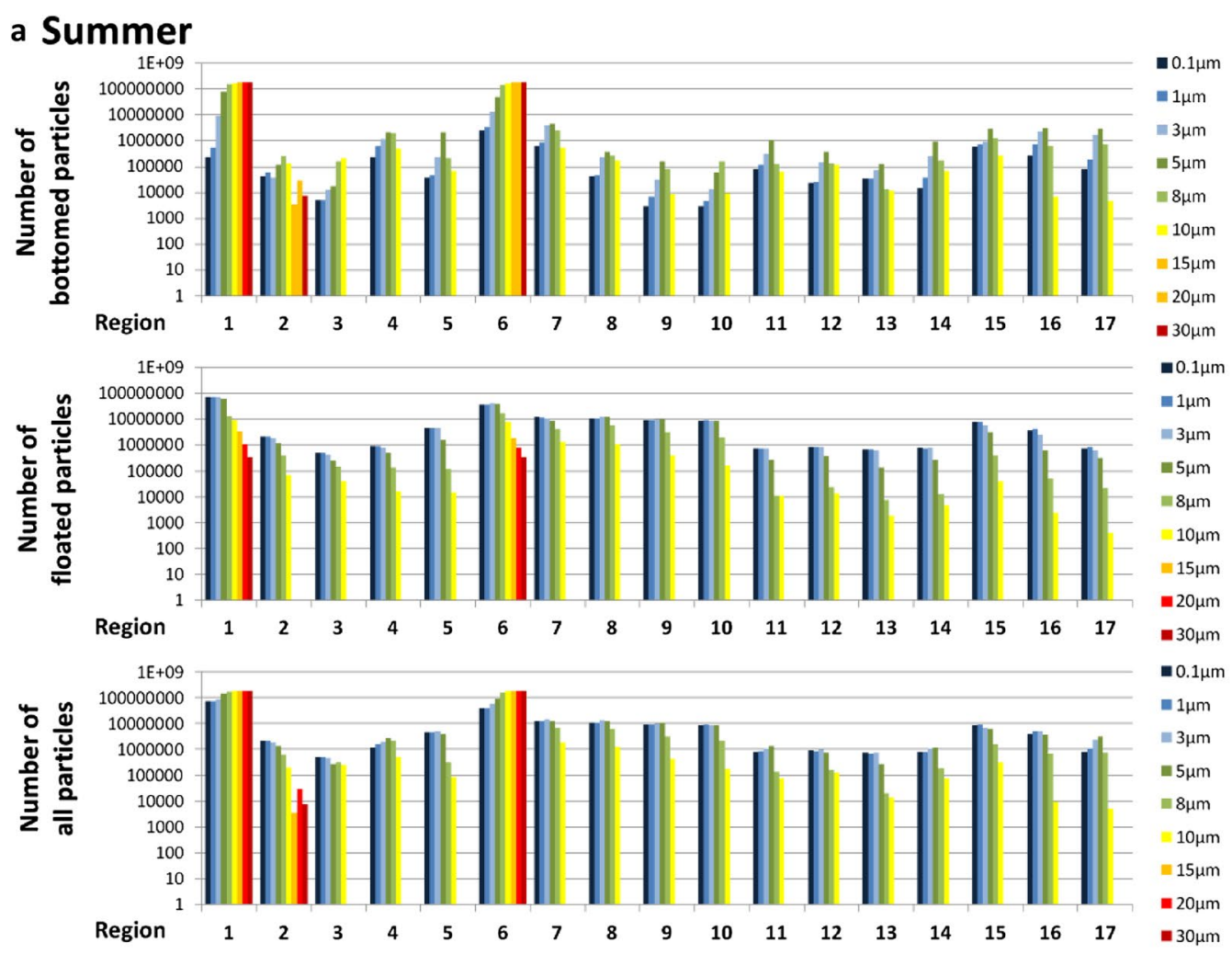

\section{b Winter}
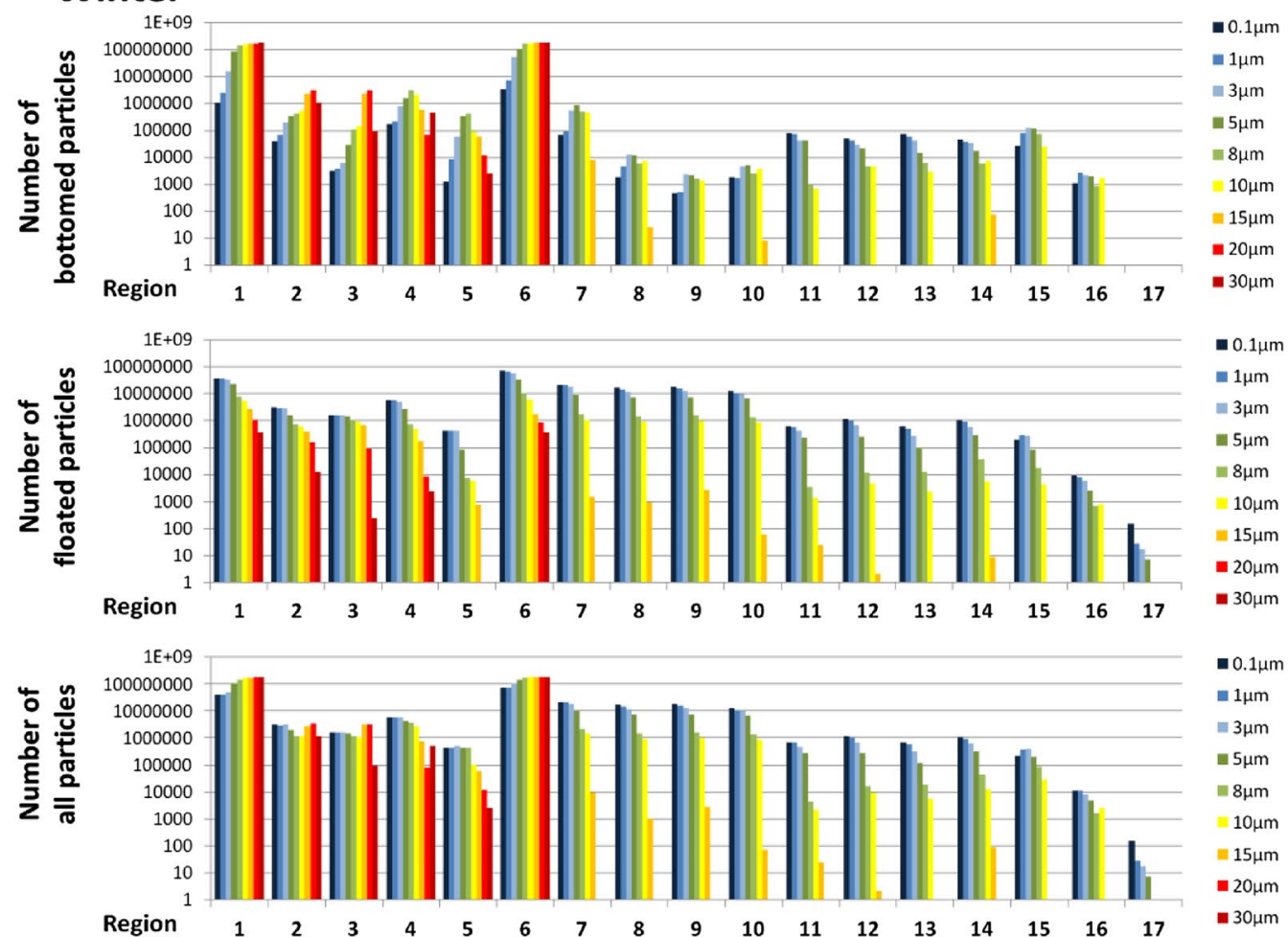

Fig. 4 Numbers of soil particles by region, particle diameter, and particles states (bottomed and floated) integrated in $\mathbf{a}$ summer and $\mathbf{b}$ winter 
of bottomed particles was high in the east side. In winter, for the Sakiyama bay, large particles moved from the river mouths over a broad region of the bay. Also, for Amitori bay, large particles moved from the river mouths to the inner bay, although the region over which they were distributed was smaller than that for Sakiyama bay. For the Sakiyama bay, numbers of both bottomed and floated particles were higher in the west side than those in the east side. For the Amitori bay, the total number of soil particles was high in the central bay, but the number of bottomed particles was high in the west side. These characteristics of soil particle distributions and movements in winter were remarkably different from those in summer. The strong ENE winds in winter have the same impact on both bays. Therefore, the lengths in which the winds affect the soil transport are almost same for both bays. However, the sizes and depths of both bays are different (i.e., Sakiyama bay is smaller and shallower than Amitori bay). As the result, difference of soil particle transports between both bays in winter is considered to be caused.

Figure 5 shows the final and integrated numbers of soil particles that were exchanged between Sakiyama and Amitori bays in the summer and winter seasons. The final and integrated values mean the values at the end of the simulations and those integrated during

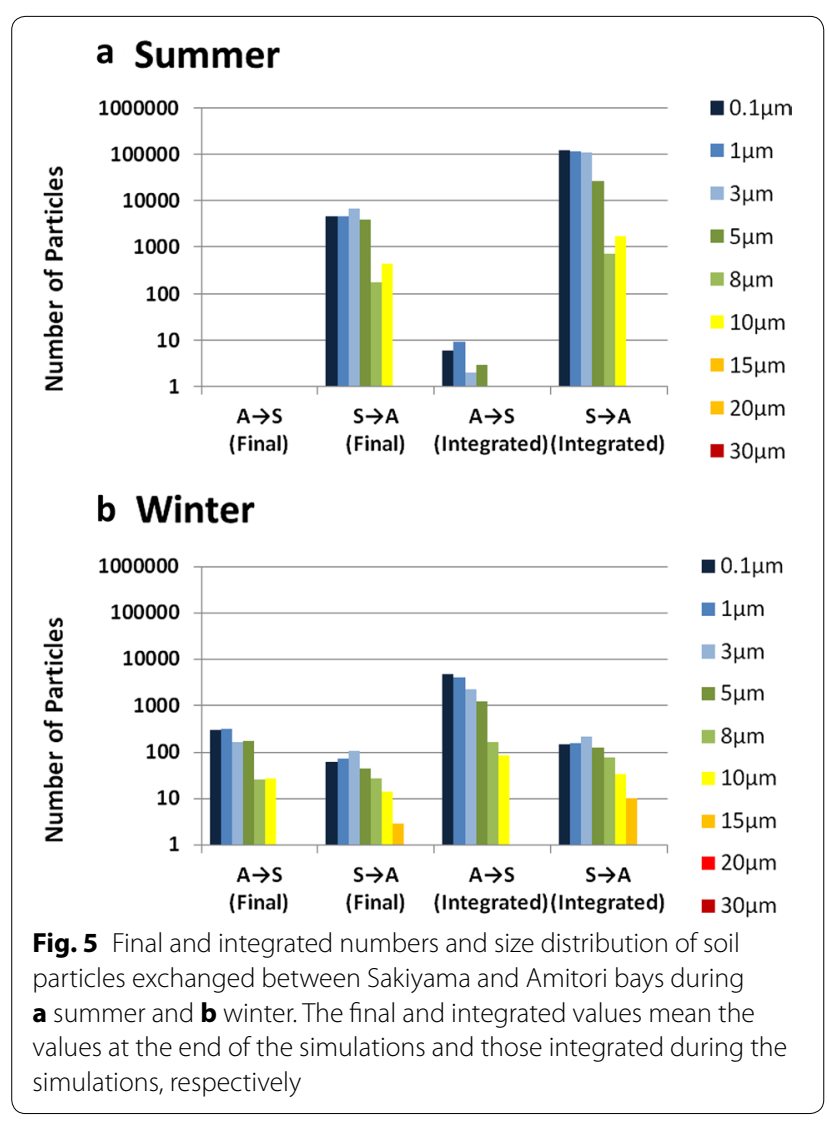

the simulations and are shown as a representative of instant and averaged values, respectively. For the soil particle exchange numbers, regions 13,14 , and 17 of the Amitori bay were excluded because they include open ocean regions. In summer, soil particles moved mainly from the Sakiyama to the Amitori bay. On the other hand, in winter, soil particles moved mainly from the Amitori to the Sakiyama bay. However, in winter, movements from the Sakiyama to the Amitori bay also occurred for large particles, which is not observed in the other cases in this study. This fact agrees with the characteristics seen in Fig. 4, which shows that in winter for the Sakiyama bay, large particles moved from the river mouths to cover a broad region of the bay. Comparing the final values with the integrated values, we can see that in summer, the final values from the Amitori to the Sakiyama bay were not observed but the integrated values are present. In winter, the final values from the Amitori to the Sakiyama bay are on the same order of magnitude as those in the reverse direction, but the integrated values from the Amitori to the Sakiyama bay are a few orders of magnitude larger than those in the reverse direction.

Figure 6 shows time series of wind speed and direction observed at point A (Fig. 2) during summer and winter. The averaged wind speed in winter is about two times larger than that in summer because of the existence of strong seasonal wind from Asian continent in winter. The averaged wind direction is SSE in summer and

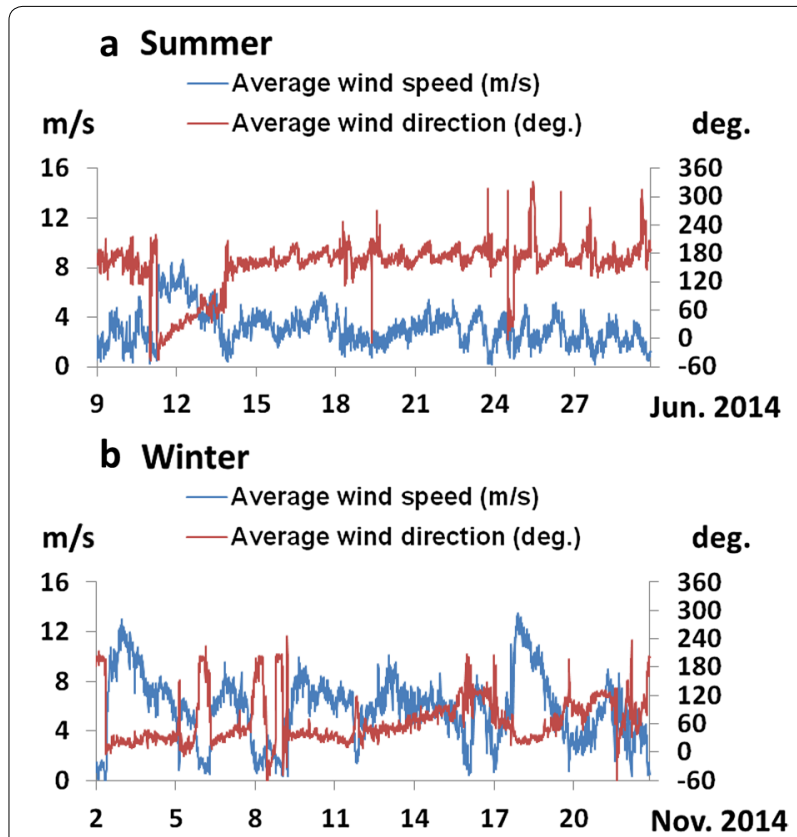

Fig. 6 Time series of wind speed and direction observed at point A (Fig. 3) in a summer and b winter 
ENE in winter and is almost constant except for temporal variations, such as the passage of low-pressure systems, such as the storm event of June 12, 2014. The respective averaged values of wind speed and direction are $3.1 \mathrm{~m} / \mathrm{s}$ and $160^{\circ}$ in summer and $5.8 \mathrm{~m} / \mathrm{s}$ and $73^{\circ}$ in winter (see also Table 1). Comparing the features of wind speed and direction (Fig. 6) with those of soil particles seen in the snapshot (Fig. 3), in summer, the soil particles released from the river mouth at the inner bay flow in the direction of the wind (SSE). In winter, the spread soil particles shift to the direction of the wind (ENE) in both bay but, in Amitori bay, seem to be trapped in the center of the bay. Figure 7 shows the ocean current in winter. In Amitori bay, the current flows to the west coast at $0 \mathrm{~m}$, but it flows to the eastern coast at 30 and $50 \mathrm{~m}$ as the return flow. This means that the current rotate in the direction of depth. As time passes, the soil particles are trapped to the rotating current. In Sakiyama bay, this mechanism does not occur because the bay is shallow (the depth of most part of the bay is within a few meters and the maximum is about $13 \mathrm{~m}$ at a reef pool with radius of $200 \mathrm{~m}$, Kawana 1990). In addition, comparing the features of wind speed and direction with those of soil particles seen in Figs. 4 and 5 , the difference in large particle movements for both bays with season is considered to be controlled mainly by the difference of wind speed with seasons. Furthermore, the difference in the number of soil particles exchanged between the Sakiyama and Amitori bays with season is

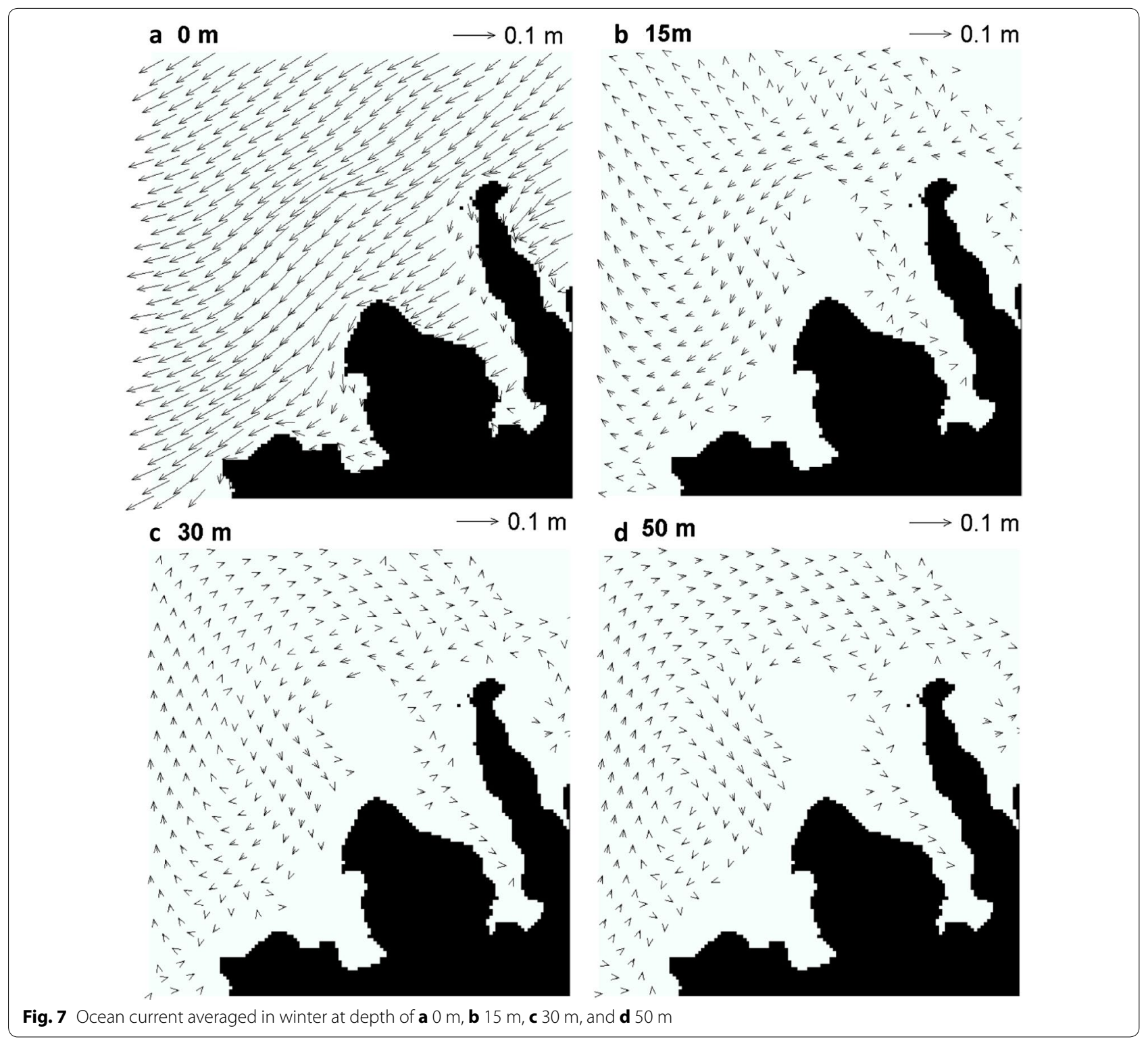


considered to be determined mainly by the difference of wind direction with seasons. There is a certain amount of soil particle transport from Sakiyama bay to Amitori bay in winter which is in the inverse direction of the winds. However, in Fig. 7, we can see that averaged ocean current, especially in offshore, flows from Sakiyama bay to Amitori bay at 30 and $50 \mathrm{~m}$ though it flows from Amitori bay to Sakiyama bay at surface. In addition, averaged wind direction was ENE in winter but, as seen in Fig. 6, the wind directions in winter were largely changed and become almost south around 2nd, 6th, 8th, 16th, 19th, and 22th, November. For the above reasons, the soil particle transport from Sakiyama bay to Amitori bay in winter is considered to be occurred in winter. As the result, the features in transport properties of soil particles in the Sakiyama and Amitori bays and the soil particle exchange properties between the bays are explainable mainly by seasonal differences in wind speed and direction, but the combination among seasonal differences in wind speed and direction, wind-driven current and topography is also important for them.

However, there are some points to be improved to assess more precisely the actual states of soil particle transport in and exchange between the Sakiyama and Amitori bays. In particular, in the numerical simulations for the Painta and Ubo rivers in the Sakiyama bay, the flow rate used for winter was the same as that used for summer because we were unable to obtain a winter observational value, required as in input for the numerical model. In addition, the critical Shields number was constant over the whole region in the numerical simulations conducted here, but observational values, which depend on the locations, should be used in further studies.

\section{Conclusions}

Our target region is the only oceanic nature conservation area in Japan, and the conservation and the assessment of environmental impact there are urgently and critically needed, but have not been investigated thoroughly in the region, especially in Sakiyama bay. For the basic information to the analysis, we provided transport properties of soil particles in the region in this study.

The Sakiyamawan-Amitoriwan nature conservation area, which was designated as a nature conservation area in 2015 (Ministry of the Environment, Government of Japan 2015a), critically requires an immediate environmental impact assessment of the coastal marine ecosystems, such as those containing reef-building corals and $E$. acoroides. As basic information to the analysis, we provided transport properties of soil particles in the region in this study. Here, we conducted atmosphere-oceanriver observations and numerical simulations for the area to understand the transport properties of soil particles in the study area and the exchange of soil particles between the Sakiyama and Amitori bays during summer and winter.

The results are summarized as follows: (1) for both bays, soil particles tended to accumulate on the east side in summer and on the west side in winter; (2) for both bays, in summer, large particles $(\geq 15 \mu \mathrm{m})$ did not move from the vicinity of the river mouths, but in winter, large particles moved from the river mouths to the inner parts of the bays; and (3) soil particles moved mainly from the Sakiyama to the Amitori bay in summer, but the direction was reversed in winter. These features are explainable mainly by seasonal differences in wind speed and direction, but the combination among seasonal differences in wind speed and direction, wind-driven current and topography is also important for them. For Amitori bay, we have conducted studies on the soil particle impact on coastal marine ecosystems such as corals (e.g., Murakami et al. 2012; Shimokawa et al. 2014b, 2015, 2016; Ukai et al. 2015) and E. acoroides (e.g., Murakami et al. 2014, 2015a, b; Nakase et al. 2015, 2016). Those results provide the basic information about whether the control of soil input from the rivers should be done or not and how much it should be done. Therefore, the results are expected to be useful to assess soil particle impact on coastal marine ecosystems and their effective conservation in the Sakiyamawan-Amitoriwan nature conservation area.

In the future, we aim to conduct the observations related to the flow rate and critical Shields number mentioned in the end of the previous section and to try to assess more precisely the soil particle impact on coastal marine ecosystems. Such results will enable us to clarify the relationship between the distributions of coastal marine ecosystems, such as those containing reef-building corals and E. acoroides, and physical factors, including the soil particle environment in the Sakiyamawan-Amitoriwan nature conservation area.

\section{Abbreviation}

CCM: Coastal ocean Current Model.

\section{Authors' contributions}

SS and TM carried out the numerical simulations. HK and AM carried out the observations. All authors discuss the obtained results and drafted the manuscript in cooperation. All authors read and approved the final manuscript.

\footnotetext{
Author details

1 Storm, Flood and Landslide Research Division, National Research Institute for Earth Science and Disaster Resilience, 3-1 Tennodai, Tsukuba, Ibaraki
} 
305-0006, Japan. ${ }^{2}$ Okinawa Regional Research Center, Tokai University, 870-277 Uehara, Taketomi, Yaeyama, Okinawa 907-1541, Japan.

\section{Acknowledgements}

The authors greatly appreciate Mr. Ken Sakihara, Ms. Seina Miyauchi, Ms. Mayumi Suzuki, Mr. Yuichi Yoshioka, and Mr. Yuji Kitahara of Tokai University for their sincere help. The authors are grateful also to American Geophysical Union for permission to reuse the figure of Shimokawa et al. (2014b).

\section{Competing interests}

The authors declare that they have no competing interests.

\section{Availability of data and materials}

The datasets during and analyzed during this study are available from the corresponding author on reasonable request.

\section{Consent for publication}

The study does not include any personal data.

\section{Declarations}

The authors declare that they have no issues relating to the journal policies and no competing interests and confirm that all authors read and approved the manuscript for submission and the content of the manuscript has not been published, or submitted.

\section{Ethics approval and consent to participate}

The study does not include any personal data.

\section{Funding}

This study was supported by a corporative research project of the Okinawa Regional Research Center of Tokai University, Penta-Ocean Construction Co. Ltd, National Research Institute for Earth Science and Disaster Prevention, and the Japan Society for the Promotion of Science through Grant No. 25400465.

\section{Appendix 1: Distributions of corals and Enhalus acoroides in the Sakiyama and Amitori bays}

In Sakiyama bay (Shimokawa et al. 2016), region 1 (see Fig. 2) has mud floor with no coral and E. acoroides. Massive corals and $E$. acoroides (see below) are mainly in region 2 and south parts of regions 4 and 5 . Branching corals are mainly in south part of region 3 . In mouth of the bay (north parts of regions 3,4 , and 5), various types of corals exist.

In Amitori bay (Shimokawa et al. 2014b), regions 8, 9, and 10 are deep (maximum $70 \mathrm{~m}$ ) with little corals and no $E$. acoroides. E. acoroides existed formerly in region 6, east part of region 7 , and region 15 , but they decrease at preset (Nakase et al. 2015, 2016). Various types of corals exist in all regions except for regions 8,9 , and 10. Tabular corals tend to exist in the central and mouth parts of the bay. Branching corals do in the central and inner parts of the bay. Massive corals do in the inner part of the bay.

This region is a nature conservation area and uninhabited. Therefore, the effect of artificial developments is little. However, high water temperature with global warming largely affects the distributions of corals. Recently, in summer of 2016, high water temperature caused severe damage to corals (e.g., Murakami 2017). The above distributions of corals are those before 2015 .

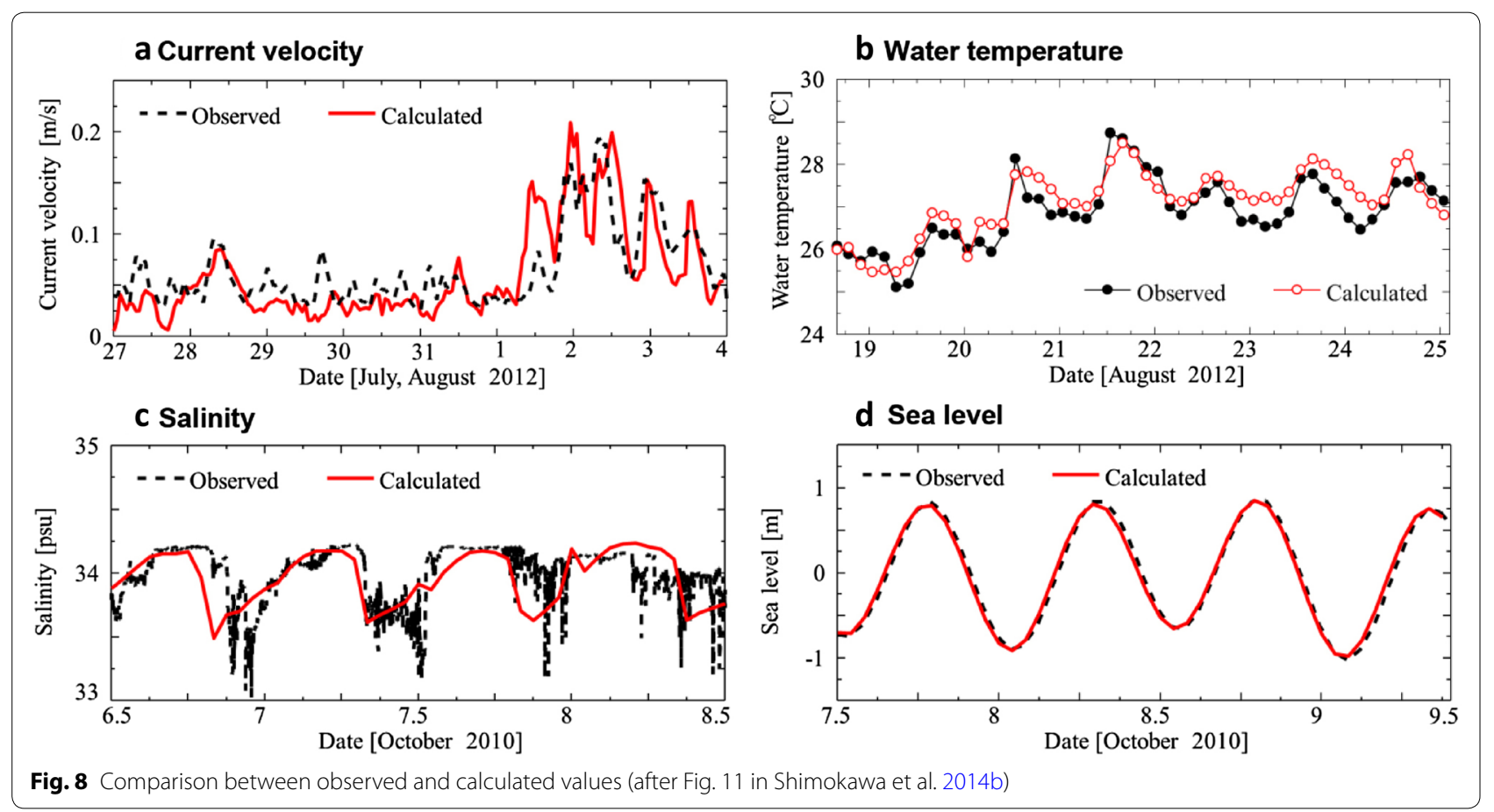


E. acoroides is a monotypic genus of marine flowering plant that is a large seagrass native to coastal areas of the tropical Indian and Western Pacific Oceans; its northern distribution limit is the ocean area surrounding the Yaeyama Islands, Japan, including Iriomote Island and most of communities of sea glass in this region are those of $E$. acoroides. It is classified as endangered species II in the Red Data Book (Ministry of the Environment, Government of Japan 2015a). The recent decrease is reported in Nakase et al. $(2015,2016)$. The stressor has not been specified, but, at least in this region, some documents report that it may be predations by sea turtles (Ministry of the Environment, Government of Japan and Okinawa regional research center, Tokai University 2016, 2017). On the other hand, the sea turtles increase recently in this region because of their protection activities and the decrease of the fishers.

\section{Appendix 2: Verification of precision for CCM}

Figure 8 shows the observed and calculated current velocities, water temperature, salinity, and sea level (Shimokawa et al. 2014b). The current velocities were observed at point B (Fig. 2), and water temperature, salinity, and sea level were observed at point A (Fig. 2). The depths of current velocities, water temperature, and salinity are $3.4,3.0$, and $1.0 \mathrm{~m}$, respectively. The period of a quantity in the figure corresponds to the period of the observation of the quantity. As shown in the figure, CCM can reproduce the current velocities, water temperature, salinity, and sea level observed in Amitori bay with high precision. The biases and root mean square errors of the current velocities are 0.0043 and $0.030 \mathrm{~m} / \mathrm{s}$, respectively. Those of the water temperature are 0.27 and $0.43{ }^{\circ} \mathrm{C}$, respectively. Those of the salinity are 0.063 and $0.21 \mathrm{PSU}$, respectively. Those of the sea level are 0.0061 and $0.063 \mathrm{~m}$, respectively.

In this study, we used the Lagrangian particle tracing analysis to analyze the soil transport in the Sakiyamawan-Amitoriwan nature conservation area. The method can calculate soil distribution patterns with a precision of current velocities which CCM can calculate with high precision as mentioned above.

\section{Publisher's Note}

Springer Nature remains neutral with regard to jurisdictional claims in published maps and institutional affiliations.

Received: 23 March 2017 Accepted: 18 August 2017

Published online: 24 August 2017

\footnotetext{
References

Kawana T (1990) Geomorphology, geology, climate and marine conditions in and around the Sakiyama bay, Iriomote Island, The South Ryukyus,
}

Japan. In: Report of investigation for Sakiyamawan nature conservation area (Ministry of the Environment, Government of Japan), pp 9-26 (in Japanese with English abstract)

Kawasaki K, Murakami T, Toda K, Okubo Y (2008) Particle tracking analysis on seawater exchange and soil transport in Ise bay area at Tokai heavy rain. Annu J Coast Eng 55:986-990 (in Japanese with English abstract)

Matsumoto K, Takanezawa T, Ooe M (2000) Ocean tide models developed by assimilating TOPEX/POSEIDON altimeter data into hydrodynamical model: a global model and a regional around Japan. J Oceanogr 56:567-581

Ministry of the Environment, Government of Japan (2015a) Red Data Book 2014-9 (in Japanese)

Ministry of the Environment, Government of Japan (2015b) Plan for Sakiyamawan-Amitoriwan nature conservation area (in Japanese)

Ministry of the Environment, Government of Japan and Okinawa Regional Research Center, Tokai University (2016) Report on decrease of Enhalus acoroides in Sakiyamawan-Amitoriwan nature conservation area, Iriomote Island, 2015 (in Japanese)

Ministry of the Environment, Government of Japan and Okinawa Regional Research Center, Tokai University (2017) Report on decrease of Enhalus acoroides in Sakiyamawan-Amitoriwan nature conservation area, Iriomote Island, 2016 (in Japanese)

Murakami T, Yoshino J, Yasuda T, lizuka S, Shimokawa S (2011) Atmosphereocean-wave coupled model performing 4DDA with a tropical cyclone bogussing scheme to calculate storm surges in an inner bay. Asian J Environ Disaster Manag 3:217-228

Murakami T, Ukai A, Kohno H, Mizutani A, Shimokawa S, Nakase K, Yasuda T (2012) Relationships between distributions of coral and physical environments in Amitori bay, Iriomote Island, Japan. Ann J Civil Eng Ocean B3 68:1133-1138 (in Japanese with English abstract)

Murakami T, Ukai A, Noguchi K, Kohno H, Mizutani A, Shimokawa S, Nakase K, Yoshino J (2013) Numerical analysis of sediment transport in Amitori bay, Iriomote Island, Japan. Ann J Civil Eng Ocean B3 69:928-933 (in Japanese with English abstract)

Murakami T, Kohno H, Iwasaki A, Kuramochi T, Shimokawa S, Kimura K (2014) Particle tracking analysis based on ecological investigation of seeds of Enhalus Acoroides in Amitori bay. Ann J Civil Eng Ocean B3 70:1074-1079 (in Japanese with English abstract)

Murakami T, Kohno H, Tamamoto M, Mizutani A, Shimokawa S (2015a) Numerical Analysis of seed dispersal of Enhalus Acoroides in the northwest sea area of Iriomote Island, Japan. Ann J Civil Eng Ocean B3 71:951-956 (in Japanese with English abstract)

Murakami T, Kohno H, Tamamoto M, Mizutani A, Shimokawa S (2015b) Numerical analysis of fructification dispersal of Enhalus acoroides in the northwest sea area of Iriomote Island, Japan. Ann J Civil Eng Ocean B2 71:1351-1356 (in Japanese with English abstract)

Murakami T, Shimokawa S, Yoshino J, Yasuda T (2015c) A new index for evaluation of risk of complex disaster due to typhoons. Nat Hazards 75:29-44. doi:10.1007/s11069-015-1824-5

Murakami T, Kohno H, Nakamura M, Tamamura N, Mizutani A, Shimokawa S (2017) Bleaching of vertically distributed corals in Amitori bay of Iriomote Island. Ann J Civil Eng Ocean B3 73 (in press) (in Japanese with English abstract)

Nakase K, Murakami T, Ukai A, Mizutani A, Shimokawa S, Kohno H (2015) Distribution analysis of Enhalus acoroides vegetation, using hydraulic model, in the northwest sea area of Iriomote Island, Okinawa, Japan. Ann J Civil Eng Ocean B3 71:957-962 (in Japanese with English abstract)

Nakase K, Murakami T, Kohno H, Mizutani A, Ukai A, Shimokawa S (2016) Estimation of the Enhalus acoroides distribution using monthly condition of external forces by wave model in northwest coast of the Iriomote Island. Ann J Civil Eng Ocean B2 72:429-434 (in Japanese with English abstract)

Rubey WW (1933) Settling velocities of gravel, sand and silt particles. Am J Sci 25:325-338

Shimokawa S, Murakami T, lizuka S, Yoshino J, Yasuda T (2014a) A new typhoon bogussing scheme to obtain the possible maximum typhoon and its application for assessment of impacts of the possible maximum storm surges in Ise and Tokyo bays in Japan. Nat Hazards 74:2037-2052. doi:10.1007/s11069-014-1277-2

Shimokawa S, Murakami T, Ukai A, Kohno H, Mizutani A, Nakase K (2014b) Relationship between coral distributions and physical variables in Amitori 
bay, Iriomote Island, Japan. J Geophys Res Oceans 119:8336-8356. doi:10.1002/2014JC010307

Shimokawa S, Kohno H, Murakami T, Mizutani A, Shibayama T, Yamamoto Y, Ukai A, Nakase K (2015) Relationship between massive coral distribution and physical variables in Amitori bay, Iriomote Island, Japan. Ann J Civil Eng Ocean B3 71:969-974 (in Japanese with English abstract)

Shimokawa S, Kohno H, Murakami T, Miyauchi S, Suzuki M, Mizutani A (2016) Relation between coral distributions and physical variables in Sakiyama bay, Iriomote Island, Japan. Ann J Civil Eng Ocean B2 72:1435-1440 (in Japanese with English abstract)
Ukai A, Kohno H, Kohta K (2012) Database on environmental information (sea depth, land height and wave height) in Amitori bay, Iriomote Island, Japan. Study Rev Iriomote Is| 2011:49-60 (in Japanese)

Ukai A, Murakami T, Mizutani A, Nakase K, Shimokawa S, Kohno H (2015) Estimation technique of spatial coral distribution in Amitori bay, Iriomote Island, Japan. Ann J Civil Eng Ocean B3 71:963-968 (in Japanese with English abstract)

Yanagi T (2001) How do materials move in the ocean. In: Coastal oceanography, vol 2. Kouseisha-kouseikaku Corporation, Tokyo (in Japanese)

\section{Submit your manuscript to a SpringerOpen ${ }^{\circ}$ journal and benefit from:}

- Convenient online submission

- Rigorous peer review

- Open access: articles freely available online

- High visibility within the field

- Retaining the copyright to your article 